\title{
Effect of Twenty four week Football Training on Flexibility, Agility and Endurance of Junior School Boys
}

\author{
N. R. Ramkumar \\ Director of Physical Education, Amet University, Chennai, Tamil Nadu, India \\ E-Mail: ram.sportive@gmail.com
}

\begin{abstract}
The purpose of this study was to find out the effect of twenty four week Football training on flexibility, agility and endurance of Junior School boys. The study was conducted on thirty $(\mathrm{N}=30)$ Football players who were randomly selected from various Schools in Tamil Nadu, India during 20172018. The age of the subjects were ranged between 14 to 16 . The selected players was assigned in to two groups of fifteen each (n=15), Group -I underwent Football training, and Group -II acted as Control. Flexibility, Agility and Endurance were selected as dependent variables. Flexibility was assessed by Sit \& Reach test, Agility was assessed by $4 \times 10 \mathrm{~m}$ Shuttle Run and Cardio Respiratory Endurance was assessed by Cooper's 12 Minutes Run/Walk test. The experimental group underwent the training for 24 weeks. All the subjects were tested prior to and immediately after the training period of twenty four weeks for all the selected variables. The data collected data from the three groups prior to and immediately after the training programme on the selected criterion variables were statistically analyzed with Analysis of Covariance (ANCOVA). In all the cases 0.05 level of confidence was fixed to test the hypotheses. Flexibility, Agility and Endurance showed significant difference between the groups. Football training group showed better performance than Control group.
\end{abstract}

Keywords: Flexibility, Agility and Endurance

\section{INTRODUCTION}

Training is good for the development of the cardiovascular system. "It enables athletes to recover from tough workouts and helps to develop the capacity to increase repetitions". (Singh, 1991).

"Training improves the functioning of the circulatory, respiratory and the muscular systems, while practice is largely aimed at improving the control of muscular activity by the nervous systems" (Kenneth, 1976).

A football player needs to master many different skills for example football moves, shooting, passing etcetera. In order to be successful on the football field. Once a player learns a skill he will also need to maintain it. The best way for doing that is to participate in various drills. The fundamental thing a football player need to know about football drills is that he really needs to work hard during them in order to develop their skills.

Drills are pretty general, like passing, shooting, dribbling with ball and without ball drills etcetera. Football drills are one of the vehicles that develop great football players, whether the drills are done alone in a team setting. Proper performance of a drill is a key to the overall success of that particular football drill. It's not the drill alone that delivers successful footballers and teams. Every drill must be approached with a multi faceted effort. Football drills comes in all sizes and shape. They are done with the ball and without ball. It is important to note that some drills must be done as a team and other drills can be done as an individual. The advantages of conditioning with the ball at feet include reduced boredom, increased technical work, improved teamwork and more. Using small and large sided games is an effective strategy (Owen, 2011).

\section{METHODOLOGY}

The purpose of this study was to find out the effect of twenty four week Football training on flexibility, agility and endurance of Junior School boys. The study was conducted on thirty $(\mathrm{N}=30)$ Football players who were randomly selected from various Schools in Tamil Nadu, India during 2014-2015. The age of the subjects were ranged between 14 to 16 . The selected players was assigned in to two groups of fifteen each $(n=15)$, Group -I underwent Football training, and Group -II acted as Control. Flexibility, Agility and Endurance were selected as dependent variables. Flexibility was assessed by Sit $\&$ Reach test, Agility was assessed by 4x10 m Shuttle Run and Cardio Respiratory Endurance was assessed by Cooper's 12 Minutes Run/Walk test.

The experimental group underwent the training for 24 weeks. All the subjects were tested prior to and immediately after the training period of twenty four weeks for all the selected variables. The data collected data from the three groups prior to and immediately after the training programme on the selected criterion variables were statistically analyzed with Analysis of Covariance (ANCOVA). In all the cases 0.05 level of confidence was fixed to test the hypotheses. Flexibility, Agility and Endurance showed significant difference between the groups. Football training group showed better performance than Control group.

\section{RESULTS AND DISCUSSION}

The Analysis of covariance (ANCOVA) on Flexibility, Agility and Endurance of Football training group and Control group have been analyzed and presented in Table I. 
TABLE I ANALYSIS OF COVARIANCE ON FLEXIBILITY, AGILITY AND ENDURANCE OF FOOTBALL TRAINING GROUP AND CONTROL GROUP

\begin{tabular}{|c|c|c|c|c|c|c|c|}
\hline \multirow{2}{*}{$\begin{array}{c}\text { Certain } \\
\text { Variables }\end{array}$} & \multicolumn{2}{|c|}{ Adjusted Post test Means } & \multirow{2}{*}{$\begin{array}{l}\text { Source of } \\
\text { Variance }\end{array}$} & \multirow{2}{*}{$\begin{array}{l}\text { Sum of } \\
\text { Squares }\end{array}$} & \multirow[b]{2}{*}{ df } & \multirow{2}{*}{$\begin{array}{c}\text { Mean } \\
\text { Squares }\end{array}$} & \multirow{2}{*}{$\begin{array}{c}\text { 'F' } \\
\text { Ratio }\end{array}$} \\
\hline & $\begin{array}{c}\text { Football Training } \\
\text { Group-(I) }\end{array}$ & $\begin{array}{c}\text { Control Group } \\
\text { (II) }\end{array}$ & & & & & \\
\hline \multirow{2}{*}{ Flexibility } & \multirow{2}{*}{16.20} & \multirow{2}{*}{13.53} & Between & 53.33 & 1 & 53.33 & \multirow{2}{*}{$165.77 *$} \\
\hline & & & With in & 8.69 & 27 & 0.32 & \\
\hline \multirow{2}{*}{ Agility } & \multirow{2}{*}{9.90} & \multirow{2}{*}{10.55} & Between & 3.09 & 1 & 3.09 & \multirow{2}{*}{$45.41 *$} \\
\hline & & & With in & 1.84 & 27 & 0.07 & \\
\hline \multirow{2}{*}{$\begin{array}{l}\text { Cardio } \\
\text { Respiratory } \\
\text { Endurance }\end{array}$} & \multirow{2}{*}{1623.85} & \multirow{2}{*}{1461.48} & Between & 199701.70 & 1 & 199701.70 & \multirow{2}{*}{$88.85^{*}$} \\
\hline & & & With in & 60077.30 & 27 & 2225.09 & \\
\hline
\end{tabular}

(The table value required for significance at .05 level with df 1 and 27 is 4.21)

Table I shows that the adjusted post test mean values of Flexibility, Agility and Endurance for Football Training group and Control group are 16.20, 13.53, 9.90, 10.55, 1623.85 and 1461.48 respectively. The obtained F-ratios are $165.77,45.41$ and 88.85 is more than the table value 4.21 for df 1 and 27 required for significance at .05 level of confidence.

The results of the study indicate that there is a significant difference exists among the adjusted post test means of experimental groups showing the decrease in speed and increase of Explosive power and Cardio Respiratory Endurance. From the obtained mean it may be concluded that football training group is better than control group in improving Flexibility, Agility and Endurance.

The adjusted posttest mean values of football training group and control group on Flexibility, Agility and Endurance are graphically represented in the Figure 1, Figure 2 \& Figure 3.

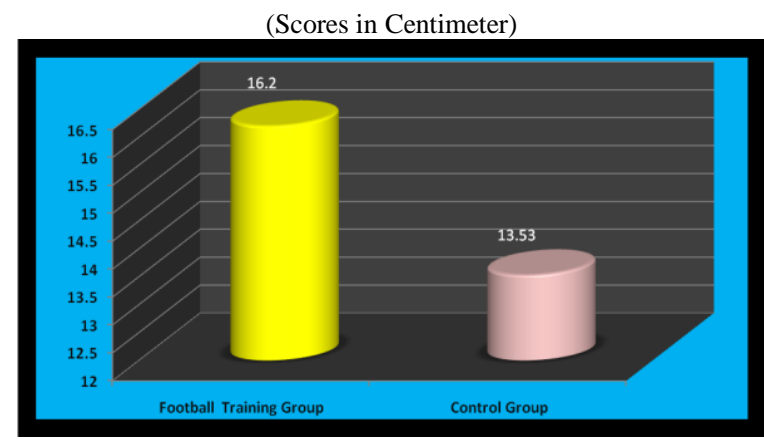

Fig. 1 Mean Values of Football Training Group and Control Group on Flexibility

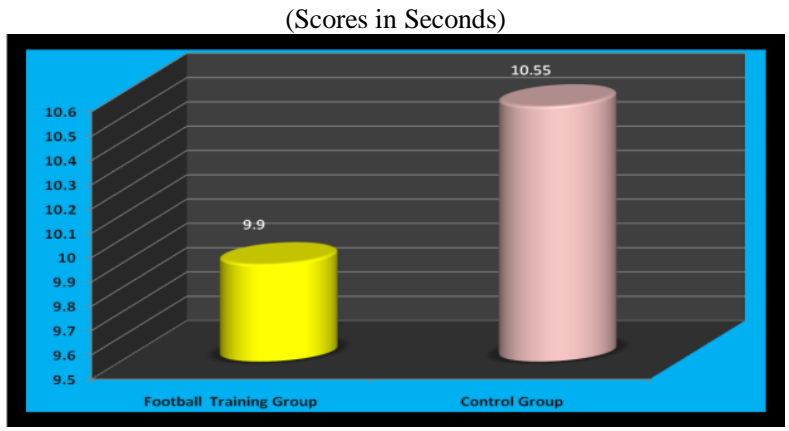

Fig. 2 Mean Values of Football Training Group and Control Group on Agility

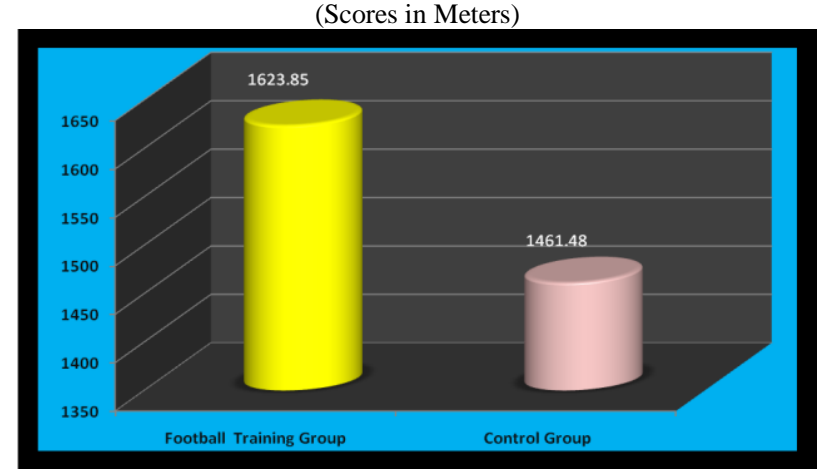

Fig. 3 Mean Values of Football Training Group and Control Group On Cardio Respiratory Endurance

\section{CONCLUSION}

From the analysis of the data, the following conclusions were drawn.

1. The Experimental groups had registered significant improvement on the selected criterion variables namely Flexibility, Agility and Endurance.

2. It may be concluded that the Football training group in improving Flexibility, Agility and Endurance.

\section{REFERENCES}

[1] Kenneth J. Doherty. (1976). Modern Track and Field, Englewood Cliffs, New Jersey: Prentice Hall Inc., 87.

[2] Owen Al, Wongdel P., McKenna M. \& Dellal A. (2011). Heart Rate Responses and Technical Comparison Between Small vs Large Sided games in elite professional soccer. Journal of Strength and Conditioning Research, 25(8), 2104-2110.

[3] Singh Hardayal, (1991). Science of Sports Training, New Delhi: D.V.S. Publications, 130. 